EESTI NSV TEADUSTE AKADEEMIA TOIMETISED 1953. II k., nr. 3

ИЗВЕСТИЯ АКАДЕМИИ НАУК ЭСТОНСКОИ ССР 1953. ТОМ II, 스 3

\title{
КАТАЛИТИЧЕСКИЕ ПРЕВРАЩЕНИЯ МАСЛЯНЫХ ФРАКЦИИ НЕФТИ НАД ПРИРОДНЫМИ ГЛИНАМИ
}

\author{
А. Ф. ДОБРЯнскиИ, \\ член-корреспондент Академии наук Әстонской ССР \\ Г. Я. ВОРОБЬЕВА, \\ кандидат хнмнческих наук
}

Многочисленные данные об изменении химического состава нефтей в зависимости от их геологического возраста позволяют сделать вывод, что сформировавшаяся нефть уже в период залегания ее в земной коре не находится в нензменном, с химической точки зрения, состоянии, а подвергается беспрерывным изменениям, от которых зависит ее состав. Эти изменения нефти происходят под влиянием ряда факторов, главными из которых являются температура и каталитическое воздействие на нефть вмещающих пород. Основную часть последних составляют алюмосиликаты, в частности глины.

Каталитическое действие алюмосиликатов, в том числе природных глин, на нефть, ее фракции и углеводороды установлено целым рядом работ. С. В. Лебедев и сотрудники $\left({ }^{9-12}\right)$ исследовали действие отбеливающей земли - флоридина на различные углеводороды; А. В. Фрост (16-18) подробно рассмотрел действие глин на углеводороды, связав это действие с образованием нефти в земной коре; Х. И. Арешидзе и Е. К. Таварткиладзе $\left({ }^{1-4}\right)$ посвятили свои исследования изучению действия глин - гумбрина и асканита на углеводороды; К. Л. Томас применил синтетические алюмосиликатные катализаторы для крекинга $\left({ }^{22}\right)$ и полимеризации $\left({ }^{23}\right)$ сложных непредельных углеводородов. На каталитическом действии алюмосиликатов основан промышленный процесс каталитического крекинга нефти и ее продуктов, который в настоящее время получил большое распространение. В то же время исследования химизма процесса каталитического крекинга, в особенности не индивидуальных углеводородов, а непосредственно нефти или ее фракций, весьма немногочисленны. Так, в 1942 году А. А. Михновская и А. В. Фрост $\left({ }^{15}\right)$ осуществили превращение крекннг-бензина над глинами при температуре $260^{\circ} \mathrm{C}$, причем получили снижение содержания непредельных углеводородов в этом бензине на $40 \%$. А. Ф. Добрянский и Б. Г. Гаврилов $\left({ }^{5}\right)$ подвергли действию гумбрнна керосин при температурах $250-300^{\circ}$, в результате чего образовалось от 7,8 до $23 \%$ (в зависимости от температуры) фракций, выкипающих при более низкой температуре, чем исходный керосин.

По исследованию же каталитического крекинга или превращений более тяжелых фракций нефти, в частности масляных, нет почти никаких данных. Только А. Ф. Добрянский, А. И. Богомолов и И. Шкляр $\left(^{6}\right)$ исследовали превращение цилиндрового масла над асканитом при тем- 
пературе $250^{\circ}$, в результате чего было получено $29,5 \%$ фракций, кипящих ниже исходного масла. А. Я. Ларин $\left(^{8}\right)$ подверг крекингу над искусственным алюмосиликатом мазуты и получил из них до $26 \%$ легкокипящих (до 200) фракций.

В развитие этих немногочисленных данных настоящее исследование имело целью изучить процесс каталитического превращения масляных фракций нефти над природными глинами при умеренных температурах, т. е. в условиях, близких к реальным условиям залегания нефти в земной коре. Последнее обстоятельство особенно важно, так как большинство упомянутых исследований проводилось при высокнх температурах, сильно отличающихся от температур земных недр. В то же время использование низких температур при одновременном увеличении продолжительности опытов давало возможность получить экспериментальные данные для подтверждения правильности гипотезы о превращении нефтей в природе, подробно изложенной А. Ф. Добрянским $\left({ }^{7}\right)$.

Объект исследований - два внда машинного масла «СУ», с разным химическим составом. Масло использовалось не целиком, а только основная его фракция - $400-500^{\circ}$, выделенная перегонкой под уменьшенным давлением. Физнко-химическая характеристика исходных продуктов представлена в таблице 1 , а данные химического состава - в таблице 2.

Таблица 1

Физико-химическая характеристика исходных продуктов

\begin{tabular}{|c|c|c|c|c|c|}
\hline \multicolumn{2}{|c|}{$\begin{array}{c}\text { Нанменование } \\
\text { исходного продукта }\end{array}$} & $\begin{array}{c}\text { Удельный } \\
\text { вес }\end{array}$ & $\begin{array}{l}\text { Коэффи- } \\
\text { циент пре- } \\
\text { домления }\end{array}$ & $\begin{array}{l}\text { Параметр } \\
\text { рефракшии }\end{array}$ & $\begin{array}{c}\text { Максимальная } \\
\text { анилиновая } \\
\text { точка }\end{array}$ \\
\hline \multirow{2}{*}{$\begin{array}{c}\text { Образец } \\
\text { N. } 1\end{array}$} & $\begin{array}{l}\text { до удаления } \\
\text { ароматич. }\end{array}$ & 0,9030 & 1,4980 & & $90,3^{\circ}$ \\
\hline & $\begin{array}{l}\text { после удале- } \\
\text { ния ароматич. }\end{array}$ & 0,8814 & 1,4803 & 1,0396 & $101,8^{0}$ \\
\hline \multirow{2}{*}{$\begin{array}{l}\text { Образец } \\
N_{2} 2\end{array}$} & $\begin{array}{l}\text { до удалення } \\
\text { ароматич. }\end{array}$ & 0,9009 & 1,4992 & & $89,7^{\circ}$ \\
\hline & $\begin{array}{l}\text { после удале- } \\
\text { ния ароматич. }\end{array}$ & 0,8847 & 1,4869 & 1,0446 & $94,5^{0}$ \\
\hline
\end{tabular}

Таблица 2

Химический состав исходных продуктов по группам углеводородов

\begin{tabular}{|c|c|c|c|c|c|c|}
\hline \multirow{3}{*}{$\begin{array}{l}\text { Наимено- } \\
\text { вание } \\
\text { исходного } \\
\text { продукта }\end{array}$} & \multirow{3}{*}{$\begin{array}{l}\text { Депрессия } \\
\text { анилиновоИ } \\
\text { точки в ० С }\end{array}$} & \multicolumn{5}{|c|}{ Групповои состав } \\
\hline & & \multicolumn{2}{|c|}{ Ароматич. В \% } & \multirow{2}{*}{$\begin{array}{l}\text { Нафтеновые } \\
\text { углеводоро- } \\
\text { ды в \% }\end{array}$} & \multirow{2}{*}{$\begin{array}{c}\text { Метановые } \\
\text { углеводоро- } \\
\text { ды в \% }\end{array}$} & \multirow{2}{*}{$\begin{array}{c}\text { Твердый } \\
\text { парафин } \\
\text { в \% }\end{array}$} \\
\hline & & $\begin{array}{c}\text { по авизи- } \\
\text { новой точке }\end{array}$ & $\begin{array}{c}\text { nо } \\
\mathrm{H}_{2} \mathrm{SO}_{4}\end{array}$ & & & \\
\hline Образец 스 1 & 11,5 & 25,7 & 27,8 & 50,6 & 23,7 & 0,3 \\
\hline Образец № 2 & 4,8 & 11,2 & 15,2 & 88,0 & 0,86 & 0,86 \\
\hline
\end{tabular}

Из данных таблицы 2 видно, что образец № 1 имеет более сложный состав, содержит примерно равные количества ароматических и метановых углеводородов и несколько больше нафтеновых углеводородов. Поэтому, с точки зрення гипотезы превращения нефтей в природе, он является более превращенным продуктом, чем образец № 2, который в 
основном состоит из нафтеновых углеводородов и почти совсем лишен метановых углеводородов.

Қаталитическое превращение исходных продуктов проводилось в металлической колонке, при непосредственном контакте этих продуктов с катализатором, в течение того или иного времени и при различной температуре. Выделяющиеся при превращении газообразные продукты улавливались в газометр, а пары конденсировались в многошариковом холодильнике и стекали обратно в реакторную колонку.

В качестве основного катализатора использовалась природная глина - гумбрин в виде небольших цилиндрообразных таблеток, объемом около $0,5 \mathrm{~cm}^{3}$. Гумбрин предварительно активировался $25 \%$ серной кислотой. Были нспробованы и другие глины: гумбрин неактивированный, кембрийская глина активнрованная и неактивированная и силикагель.

В результате превращений во всех случаях были получены новые, легкие, более низкокипящие, чем исходная, фракции, в различных количествах, в зависимости от условий превращения. Эти вновь образованные продукты явились мерилом степени и глубины превращения исходного продукта, а исследование их физико-химических свойств и группового химического состава имело целью установить направление протекания процесса каталитического превращения. С образцом № 1 было проведено несколько серий опытов, устанавливающих зависимость каталитических превращений от времени, температуры и вида катализатора. Из таблицы 3 можно получить полное представление об изменениях основной масляной фракции $400-500^{\circ}$, происшедших под влиянием активированного гумбрина в зависимости от степени и времени нагрева.

Ta6suца 3

Результаты превращений

\begin{tabular}{|c|c|c|c|c|c|c|c|}
\hline \multirow[b]{2}{*}{$\begin{array}{c}\mathrm{Na} \\
\text { опыта }\end{array}$} & \multirow[b]{2}{*}{$\begin{array}{l}\text { Teмпе- } \\
\text { ратура } \\
\text { опыта } \\
\text { B }^{\circ} \mathrm{C}\end{array}$} & \multirow[b]{2}{*}{$\begin{array}{l}\text { Продол- } \\
\text { житель- } \\
\text { ность в } \\
\text { часах }\end{array}$} & \multicolumn{4}{|c|}{ Выход новых продуктов в \% } & \multirow{2}{*}{$\begin{array}{c}\% \text { исход- } \\
\text { ной фрак- } \\
\text { щии после } \\
\text { превра- } \\
\text { щения }\end{array}$} \\
\hline & & & газа & $\begin{array}{l}\text { бензина } \\
\text { c t кип. } \\
\text { до } 200^{\circ}\end{array}$ & $\begin{array}{l}\text { керосина } \\
\text { c t кип. } \\
200-300^{0}\end{array}$ & $\begin{array}{c}\text { легких масел } \\
\text { с t кип. } \\
300-400^{\circ}\end{array}$ & \\
\hline
\end{tabular}

O 6 разещ № 1

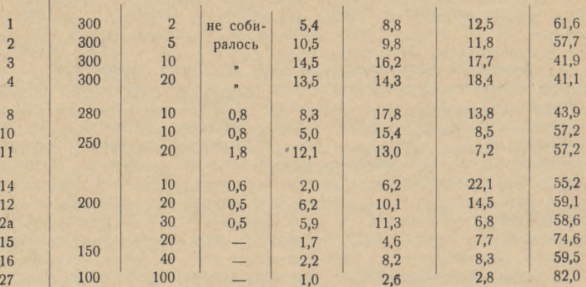

О 6 разец № 2 
Эти данные показывают, что с повышением температуры глубина превращения, претерпеваемого исходным продуктом, т. е. скорость реакщии, возрастает, но затем по мере увеличения времени нагрева и контакта с катализатором стабилизуется. Максимальные значения скорости реакции при температуре $300^{\circ}$ достигаются уже при десяти часах нагрева, а при $200^{\circ}$ - при двадщати часах. Такнм образом, оптимальные условня достигаются тем скорее, чем выше температура превращения. Но в то же время превращения имеют место уже при таких низких температурах, как 100 и $150^{\circ}$, правда за счет увеличения продолжительности опыта. А так как время геологических пернодов открывает в этом отношении большие возможности, то, с точки зрения факторов времени и температуры, можно констатировать, что нефть, залегая в недрах земли много миллнонов лет, должна претерпевать непрерывные превращения под влиянием каталитического действия вмещающих пород и температуры, если она даже порядка $100-150^{\circ}$.

Полученные экспериментальные данные находятся, таким образом, в полном соответствии с теоретическими представлениями о возможности каталитических превращений нефти в период залегания ее в земных недрах и подтверждают реальность этих превращений для температур, признанных геологами соответствующими температурам нефтяных месторождений, именно $150-200^{\circ}$.

Использованне различных катализаторов для процессов превращения масляной фракции при стандартных оптимальных условиях времени и температуры (10 часов при $300^{\circ}$ ) показало, что природа катализатора нмеет существенное значенне (таблица 4). Более активным, по сравнению с силикагелем и кембрийской глиной, оказался гумбрин, по своему химическому составу - гидроалюмосиликат типа монтмориллонита. Кроме того обнаружено, что глины, не активированные предварительной обработкой кислотой, тоже катализируют процессы превращения нефти, хотя и

Таблица 4

Результаты превращений масляной фракции над различными катализаторами при $300^{\circ}$ в течение 10 часов

\begin{tabular}{|c|c|c|c|c|c|c|}
\hline \multirow[b]{2}{*}{$\begin{array}{l}\frac{2}{3} \\
\frac{3}{2} \\
2\end{array}$} & \multirow[b]{2}{*}{ Вид катализатора } & \multicolumn{4}{|c|}{ Выход новых продуктов в \% } & \multirow{2}{*}{$\begin{array}{c}\% \text { исход- } \\
\text { нои фрак- } \\
\text { щии после } \\
\text { превра- } \\
\text { щения }\end{array}$} \\
\hline & & raза & $\begin{array}{l}\text { бензина } \\
\text { с t кип. } \\
\text { до } 200^{\circ}\end{array}$ & $\begin{array}{l}\text { керосина } \\
\text { с t кип. } \\
200-300^{\circ}\end{array}$ & $\begin{array}{l}\text { легкнх ма- } \\
\text { сел с t кип. } \\
300-400^{?}\end{array}$ & \\
\hline 18 & Без катализатора & 0,7 & 0,4 & 3,9 & 12,4 & 66,0 \\
\hline 2 & $\begin{array}{l}\text { Кембрийская глина } \\
\text { неактивнрованная }\end{array}$ & 2,5 & 2,6 & 6,2 & 12,5 & 64,9 \\
\hline 19 & $\begin{array}{c}\text { Кембрнйская глина } \\
\text { активированная }\end{array}$ & 2,6 & 4,7 & 9,4 & 9,6 & 64,7 \\
\hline 13 & $\begin{array}{l}\text { Гумбрин неактивиро- } \\
\text { ванный }\end{array}$ & 1,2 & 5,7 & 11,4 & 13,8 & 55,6 \\
\hline 17 & Силнкагель & 1,0 & 5,8 & 11,6 & 8,5 & 62,1 \\
\hline 6 & $\begin{array}{l}\text { Гумбрнн активнро- } \\
\text { ванный, отработан- } \\
\text { ный н регенериро- } \\
\text { ванный }\end{array}$ & $\begin{array}{l}\text { не соби- } \\
\text { рался }\end{array}$ & 13,6 & 17,4 & 9,8 & 47,8 \\
\hline 3 & $\begin{array}{l}\text { Гумбршн активиро- } \\
\text { ванный }\end{array}$ & , & 14,5 & 16,2 & 17,7 & 41,9 \\
\hline
\end{tabular}


менее активно. Последнее обстоятельство не имеет принципиального значения, так как сказывается только на скорости, а не на направлении реакщии. С другой стороны, холостой опыт Nㅗ 18, проведенный без катализатора, показал, что в этом случае превращение не ндет, т. е. наличие катализатора - глины имеет самое существенное значение для процессов превращения нефти, а незначительные образования керосина и легких масел, повидимому, - результат температурного крекннга.

Сравнение результатов превращения образцов № 1 и № 2 (данные опытов $8,10,25$ и 28 в таблице 3 ) показывает, что увеличение содержания в масляной фракщии полиметиленовых углеводородов (88\% в образще 소 2 и $50 \%$ в образце № 1) способствует глубине превращения этой фракщии и позволяет предположить, что главным источником образующихся бензнновых фракций являются нменно нафтеновые углеводороды, легко превращающиеся в метановые и ароматические углеводороды. Это подтверждается также данными, полученными при исследовании физикохимнческих свойств и химического состава фракщий - продуктов превращений. Часть этих данных в качестве примера представлена в таблице 5 (по опытам № 8 и № 28).

Из представленных данных видно, что более богатый нафтенами исходный продукт, т. е. ранее менее превращенный, дал в результате превращения для одноименных фракций более легкие продукты, с меньшими значениями удельного веса и коэффициента преломления и с бо̀льшим содержанием метановых углеводородов. Следовательно, этот исходный продукт подвергался значительно более глубоким превращениям и гораздо сильнее, чем продукт ранее более превращенный (образец № 1), с меньшим содержанием нафтеновых углеводородов.

Рассмотрение результатов исследования физико-химических свойств и химического состава как основных исходных, так и продуктов превращения во всех проведенных опытах позволяет констатировать, что темпе ратура, продолжительность опыта и активность катализатора способствуют как бо̀льшим изменениям исходной фракции, так и образованию новых низкомолекулярных фракций, основную массу углеводородов в которых составляют метановые и ароматические углеводороды. Послелние по сравнению с исходной фракцией количественно изменились мало, но качественно весьма значительно. Они оказались сосредоточенными во вновь образованных легких продуктах, главным образом во фракциях $200-300^{\circ}$. Максимум же содержания метановых углеводородов, в противоположность ароматическим, падает на самые легкие фракции, достигая, например, в опыте № $2754 \%$ и уменьшаясь по мере увеличения температуры кипения фракций. Своим происхождением метановые углеводороды обязаны, в основном, нафтеновым углеводородам, как это было показано выше при рассмотрении данных, представленных в таблнце 5 . Содержанне нафтеновых углеводородов во вновь образованных фракщиях оказалось сравнительно невелико, особенно по сравнению с первоначальным содержанием их в исходной фракции, и сосредоточено, больше всего, во фракции $300-400^{\circ}$.

Таким образом, можно констатировать, что в результате превращений, претерпеваемых сложными углеводородами масляных фракций нефти под влиянием природных глин, происходит разукрупнение молекул, образуются более простые соединения и, в первую очередь, простейшие метановые и ароматическне углеводороды.

Основными реакциями происходящих процессов следует считать:

1) реакции распада, т. е. крекинга сложных углеводородных молекул на более простые путем раскрытия циклов полициклических нафтенов, 


\begin{tabular}{|c|c|c|c|c|c|c|}
\hline \multirow{3}{*}{ | } & \multirow{3}{*}{ 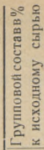 } & $\sum_{\Sigma}^{\infty}$ & $\dddot{\infty} \because-\infty=\infty$ & 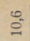 & 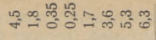 & $\underset{\sim}{\infty}$ \\
\hline & & 들 & $\because=$ 충 & $\stackrel{\infty}{\infty}$ & $1 \overline{0} 0^{\infty} \stackrel{2}{2}=0$ & $\infty_{\infty}^{\infty}$ \\
\hline & & $\begin{array}{l}\text { ('raduaн винаг } \\
\text {-arrai Eจg) JV }\end{array}$ & 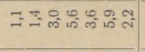 & สิ & ப் & 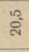 \\
\hline & \multirow{4}{*}{ 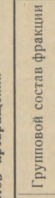 } & $\sum^{2}$ & 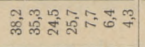 & \multirow{2}{*}{ 怤 } & 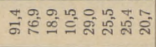 & \\
\hline 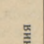 & & $\bar{z}{ }^{\circ}$ & 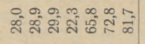 & & 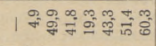 & \\
\hline 岂 & & \multirow{2}{*}{ 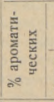 } & 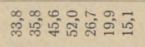 & & 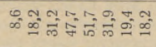 & \\
\hline 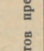 & & & 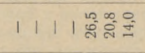 & & 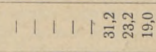 & \\
\hline 촗 & \multirow{2}{*}{ 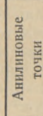 } & 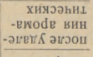 & 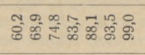 & & 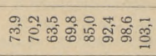 & \\
\hline 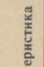 & & 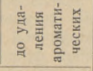 & 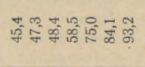 & & 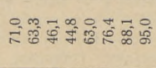 & \\
\hline 产 & \multicolumn{2}{|c|}{ 容点望 } & 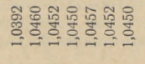 & & œ & \\
\hline 总 & \multirow{2}{*}{ 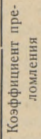 } & 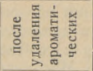 & 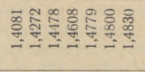 & - & 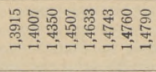 & \\
\hline $\begin{array}{l}\text { 产 } \\
\text { 产 } \\
\text { = }\end{array}$ & & 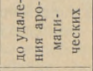 & 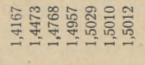 & & 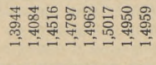 & \\
\hline \multirow{4}{*}{ 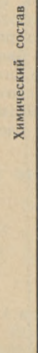 } & \multirow{2}{*}{ 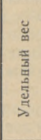 } & 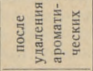 & 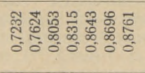 & & 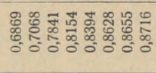 & \\
\hline & & 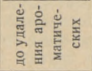 & 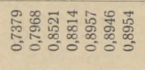 & & 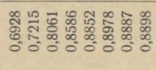 & \\
\hline & \multicolumn{2}{|r|}{ 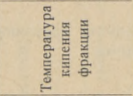 } & 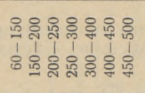 & & 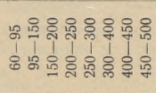 & \\
\hline & \multicolumn{2}{|r|}{ 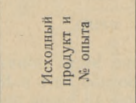 } & 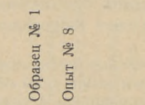 & & 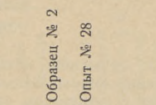 & \\
\hline
\end{tabular}


деалкилирования сложных ароматических углеводородов, разрыва углеродных цепей (отрыва боковых цепей от нафтеновых углеводородов);

2) реакции диспропорционировання водорода, освобождающегося при образовании ароматических углеводородов н, возможно, при дегидрогенизации шестичленных нафтеновых углеводородов;

3) реакции изомеризации;

4) реакции циклизации углеводородов с открытой цепью в ароматнческие.

Главным источником вновь образованных легких фракций, а в них метановых и простейших ароматических углеводородов, являются, как уже указывалось выше, нафтеновые углеводороды нефти. В то же время именно этот класс углеводородов значнтельно преобладает в подавляющем большинстве случаев над другими группами углеводородов и составляет основную массу нефти. По этой причине, а также потому, что представляло интерес изучить превращение в более простом случае деароматизированного масла, было проведено дополнительное исследование превращения последнего в тех же условиях, что и для более сложного масла (образцы № 1 и № 2). Для этой цели из такой же масляной фракщии машинного масла, предварительной обработкой серной кислотой (метод ГрозНИИ) $\left.{ }^{(19}\right)$, были удалены ароматические углеводороды и вымораживанием из раствора в дихлорэтане осаждены твердые парафнновые углеводороды. По удалении раствора и после вторичной разгонки исходный продукт (образец № 3) представлял собой фракцию 400-500, состоящую в основном из нафтеновых углеводородов, но с несомненным содержанием некоторого количества изопарафинов, удаление которых из масляных фракщий не гарантируется ни упомянутым $\left({ }^{19}\right)$, ни какими-либо другими методами.

Такое исследование представляло тем бо̀льший интерес, что и в литературе почти не встречается данных о действии алюмосиликатных катализаторов на полиметиленовые углеводороды и в особенности на сложные полициклические нафтены нефти. Так, Г. Н. Маслянский и Т. С. Берлин осуществили превращение циклогексана $\left({ }^{13}\right)$ и метилциклопентана (14) над алюмосиликатными катализаторами при температурах $515-560^{\circ}$. Они получили в обоих случаях бензол, толуол и более сложные алкилированные ароматические углеводороды: ксилол, этилбензол и другие, очевидно в результате дегидрогенизации нафтеновых углеводородов до ароматических и алкилирования последних продуктами распада первых. По данным Г. С. Блоха и К. Л. Томаса $\left({ }^{20}\right)$, основной реакцией бициклических нафтенов над алюмосиликатными катализаторами также является дегидрогенизация декалина до тетралина, а последнего до нафталина. Подобный результат получили и Б. С. Гринсфельдер с сотрудниками $\left({ }^{21}\right)$ при каталитическом крекинге циклогексана и других более сложных нафтеновых углеводородов.

Физико-химические свойства исходного продукта настоящего исследования, т. е. образца № 3, оказались следующими:

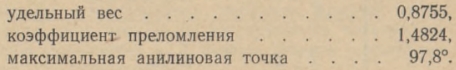

Было проведено каталитическое превращение этого образца в условиях, аналогичных изложенным выше (для образцов № 1 и № 2), т. е. в контакте с гумбрином, активированным в течение 15 часов при темпера- 
$\frac{6}{3}$

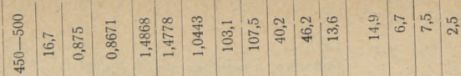

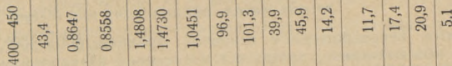

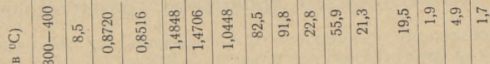

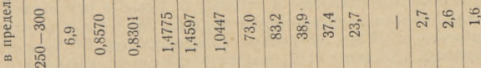

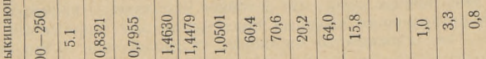
,

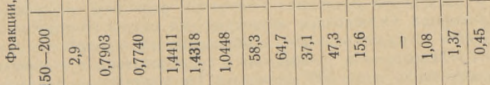

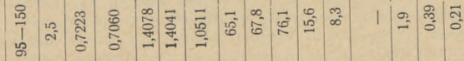

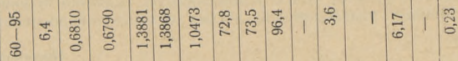

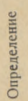

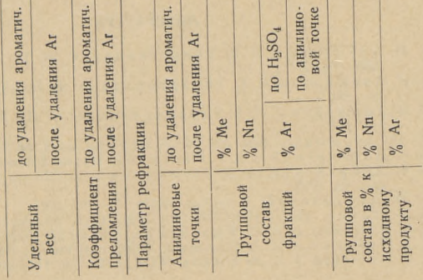


туре $210^{\circ}$. В результате было получено $32,5 \%$ фракций более легких, чем исходная, в том чнсле:

\section{газа}

бензина, выкипающего до $200^{\circ}$

керосина с пределами кипения $200-300^{\circ}$ легких масел, выкипающих при $300-400^{\circ}$

Остаток непревращенной основной фракции $400-500^{\circ}$, за вычетом остатка при перегонке, потерь и поглощенной катализатором части, составил $60,1 \%$. Продукты превращения были тщательно исследованы по их физико-химическим свойствам, фракщионному и групповому химическому составу.

Непредельные углеводороды не определялись, так как качественная реакщия на бром показала отсутствие их $(0,2 \mathrm{~N}$ раствор брома в четыреххлористом углероде не обесцвечивался от прибавления фракций). Полученные данные представлены в таблице 6 . Всего в результате проведенного каталитического превращения образца № 3 было получено: $12,6 \%$ ароматических и $38,9 \%$ метановых углеводородов. Остаток нафтеновых углеводородов составил $41 \%$, сосредоточенных в основном в исходной фракции $400-500^{\circ}(28,4 \%)$.

Из этих данных видно, что основное направление процесса каталитического превращения сложных полициклических нафтеновых углеводородов - это образование метановых углеводородов. А это значит, что происходит раскрытие циклов нафтеновых углеводородов, отрыв боковых цепей и насыщение последних благодаря реакциям диспропорционирования водорода. Оставшиеся нераскрытыми циклы полиметиленовых углеводородов дегидрогенизуются с образованием полициклических ароматических углеводородов, почему они и сосредоточены в основном в тяжелых, выкипающих выше $300^{\circ}$ фракциях. По полученным данным, из всего количества $(12,6 \%)$ образовавшихся в результате превращения ароматических углеводородов - 9,3\% падает именно на указанные фракщии.

Таким образом, полностью подтвердились высказанные выше предположения о том, что: 1) именно нафтеновые углеводороды нефти являюгся наиболее активными элементами в процессах превращения нефти; чем выше содержание их в нефти, тем более глубокие изменения она претерпевает; 2) этот класс углеводородов является основным источником метановых углеводородов легких бензиново-керосиновых фракщий.

Поступила в редакцию 7 VII 1953

\section{ЛИТЕРАТУРА}

1. Х, И, А решидзе и Е, К. Т а варткиладзе, Ж. Пр. Химии, т. 18, № 4-5, 1945 , стр. 271.

2. Х, И. А решилзе и Е. К. Таварткиладзе, Ж. Пр. Химни, т. 21, № 3, 1948 , eтp. 281 .

3. Х. И. А решидзе и Е. К. Т аварткиладзе, Ж. Пр. Химин, т. 22, № 2, 1949. стр. 119 .

4. Х. И. А решидзе, Изв, АН СССР, Отд. хим, наук, № 2, 1950 стр. 178.

5. А. Ф. Добр янский и Б. Г. Г а в илов, Научный бюллетень ЛГУ, № 23, 1949.

6. А. Ф. Добрянский, А. И. Богомолов и И. Шкляр, Ж. Пр, Химии, т. 22, вып. 10, 1949 .

7. А. Ф. Добрян ский, Геохимия нефти, Л.-М., 1948.

8. А. Я. Л а рн н, Изв. АН СССР, Отд, техн. наук, 승 10-11, 1944.

9. С. В. Лебедев и Е. П. Филоненко, ЖРХО, 57, 1925, стр. 127.

10. С. В. Лебедев н И., А. Л нвшни, ЖОХ, т. 4, вып, 1, 1934 стр. 13, 23.

11. С. В. Л е бедев и С. М. Орлов, ЖОХ, т. 5, вып. 11, 1935 стр. $1589,1595$. 
12. С. В. Лебедев н Н. А. Кудрявдев, ЖОХ, т. 5, вып, 12, 1935, стр. 1859.

13. Г. Н. Маслянски й н Т. С, Берлнн, ЖОХ, т. 16, вып, 10, 1946.

14. Г. Н. Маслянский, Е. И. Межебовская и Т, С. Берлин, ЖОХ, т. 16, вып, 11, 1946.

15. А. А. Михновская и А. В. Фрост, ДАН СССР, 37, № 7-8, 1942.

16. А. В. Ф рост, ЖОХ, т. 14, вып. 9-10, 1940.

17. А. В. Ф рос т, Успехи химин, т. 14, вып, 6, 1945.

18. А, В. Фрост, Ученые записки МГУ, вып. 86, кн. 1. Труды кафедры физ, химни, 1946.

19. Химический состав нефтей и нефтепродуктов. Труды научно-исслед. ин-та Грознефти, ОНТИ, 1935.

20. H. S. Bloch a, C. L. Thom a s, J. Am. Chem. Soc., Vol, 66, 1589, 1944.

21. B. S. Greensfeider a. H. H. Voge, Ind. Eng. Chem., Vol, 37, N8 11, 1038, 1945.

22. C. L. Thom a s, J. Am. Chem. Soc., Vol, 66, No 9, 1944.

23. C. L. Th om a s, Ind. Eng. Chem., Vol, 37, No 6, 543, 1945. 